\title{
The Meeting Places
}

\section{Flexible, reservable, and equipped}

$\mathbf{T}$

he Walker Library, which opened in 1999 ,

is a popular destination at Middle Tennessee State University (MTSU). The student enrollment in fall 2012 was 25,394 students, and the average daily gate count for the library during that time period was approximately 7,000. At over 250,000 square feet, the library is able to accommodate many different usage needs, and, since we are open from 7:00 a.m to $2: 00$ a.m, we can do it nearly all day long. We have group and individual com-

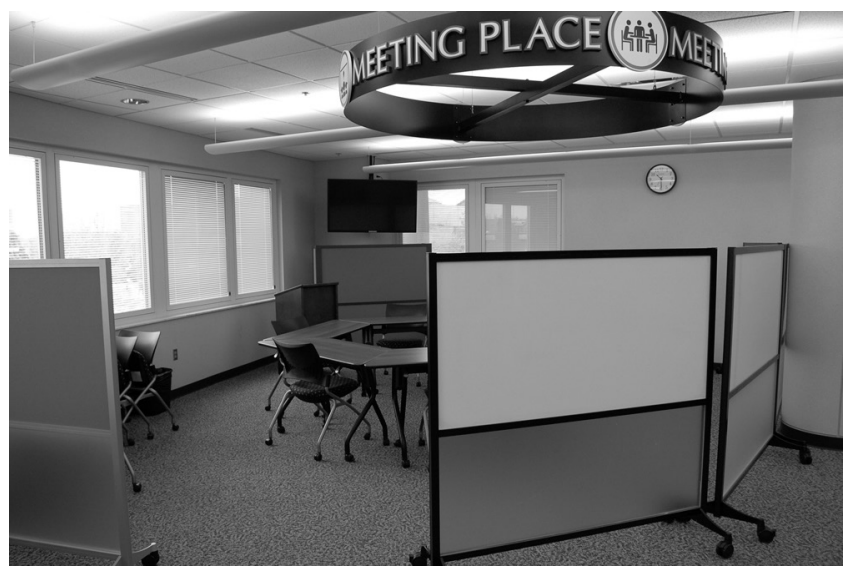

Thanks to the willingness of the User Services department to accommodate room use requests when the rooms are not needed by the library, the secret got out. The scheduling secretary is careful to balance the needs of the library with the requests of the instructors, and she only allows room use when it appears that a library instruction class will not be scheduled, but with a continual increase in both library instruction requests and room use requests, it had become clear that a new kind of space was needed in

puting zones, Meeting Place 2 sits in the corner of a large study room and can the library. presentation seat up to 15 people. Photo credit: Christy Groves. practice rooms, open collaborative study and open quiet spaces, enclosed group study rooms, and two classrooms. It was the increasing demand for the instruction spaces that inspired the development of the Meeting Places.

Classroom space is at a premium on the MTSU campus, especially 21st-century classrooms. The library's two bibliographic instruction classrooms, equipped with an instructor computer station, projector, and computer terminals for up to 36 students, had been the best kept secret on campus for faculty needing an occasional high tech class session. to room use requests by instructors, we were also fielding requests for student club meetings, human resources trainings, and campus lecture series. Meetings held on a regular schedule, such as weekly, could not usually be scheduled in the library instruction rooms because they would occupy too much time that might be needed for bibliographic

Christy Groves is head of user services, e-mail: christy. groves@mtsu.edu, and Amy York is Web services librarian at Middle Tennessee State University's Walker Library, e-mail:amy.york@mtsu.edu

(c) 2013 Christy Groves and Amy York 
instruction, but there were no other spaces in the library that were suitable for these types of meetings. Other spaces in the library were either too small, lacked suitable seating, were not equipped with computers or projectors, or were intended only for academic purposes by students (such as our group study rooms). Nonacademic meeting spaces are as rare on campus as classroom space, so when the library went through a renovation to convert the reference area to a Research Commons in 2011, we also sought a solution to the need for tech-equipped meeting spaces.

\section{Location}

The Walker Library is four stories high, and the northeastern and northwestern corners of the second to fourth floors were designed as large, open study spaces featuring a mix-
By giving these corner rooms a clear purpose, the library was able to fill a user need and protect library spaces from additional encroachment.

\section{Design}

When designing the Meeting Places, the renovation committee researched and toured several other campus libraries in the southeastern United States for inspiration. One theme that emerged from our explorations was flexibility, both in layout and in furnishings. Students (and faculty) at our inspiration libraries ${ }^{3}$ were encouraged to modify library spaces on the fly, and they were doing so and getting creative in their configurations.

We knew that for our Meeting Places to accommodate the varying needs of our patrons' gathering habits, we must provide movable

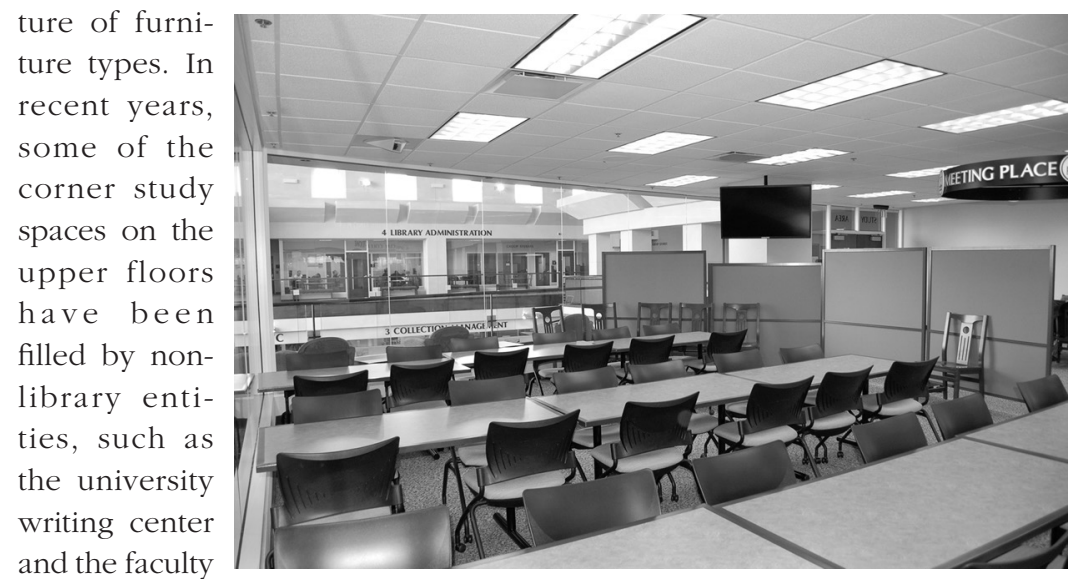
teaching and te chnology Christy Groves.

center, symptoms of the space shortage on campus. While these additional units offer significant benefits to library users, they limit future growth for library-led services or collections.

While exploring first-floor renovations for the Research Commons in 2011, staff on the renovations committee became aware of the increasing demand for classroom and meeting space in the library and decided to carve out sections of two of the remaining corner study rooms to meet this need. These spaces on the second and fourth floors became known, respectively, as Meeting Place $2^{1}$ and Meeting Place $4 .^{2}$ partitions furniture, and equipment. We worked with the design firm contracted with MTSU on our first floor Commons renovation, so when working on the Meeting Places, we were able to select furniture, tables, and fabric samples consistent with those in the Commons. Chairs and tables have wheels that can be folded for tidy out-of-the-way storage, if fewer seats are needed at a gathering. We added white board partitions, also on wheels, to the Meeting Places for students and faculty to use for creative collaboration. The partitions are movable so that patrons may define their space as they choose. We have a master floorplan that we follow, however, so near the end of each day, a library staff member returns the furniture to the master layout. This provides accountability regarding the whereabouts of 
the chairs, tables, and partitions, although to date we have encountered very few problems with furniture being relocated to other parts of the building. Periodically, a partition makes its way to another floor, but we can readily determine its proper location by consulting the master layout.

The Meeting Places are located in a portion of two much larger study rooms. Large circular signs labeled "Meeting Place" are centered over the area to define the core space. The movable partitions further demarcate the area, though as mentioned above, the partitions can be moved to expand the space. Meeting Place 2 has tables and chairs to accommodate up to 15 users, while Meeting Place 4 is much larger and is intended to seat up to 36 .

Each Meeting Place is equipped with large ceiling-mounted LCD monitors that may be connected to library or user-supplied laptops for presentation display. The library also loans a Meeting Place kit containing connector cables and presentation remotes.

\section{Policies and procedures}

The Meeting Places may be reserved online by MTSU faculty, staff, and students for up to three hours at a time and up to three months in advance. This allows instructors to hold entire classes — some of which last three hours—in the spaces and to plan a semester ahead of time. While we do not wish to see instructors use this as their weekly class space (they do have regular classroom assignments, after all), other meetings are allowed on a regular basis. For instance, the student advising office holds its weekly Academic Success Series in Meeting Place 4. Meetings do not have to be academically related, so student clubs may gather there-something that is not allowed in the group study or library instruction rooms.

Because the space is not fully enclosed, the general public may use the space without a reservation, but they may not use the equipment. Also due to the open nature of the spaces, groups within and outside of the Meeting Places must accept elevated noise levels. Groups using the Meeting Places are asked to keep their volume at "appropriate" levels, but the volume will vary according to the meeting. So far, we have not heard about noise problems from users of the Meeting Places or from groups using the spaces adjacent to them.

Our original online reservation method, a combination of a Google Calendar and an online form, required staff mediation. As the popularity of the spaces grew, we looked for a fully automated reservation system. After considering several free and paid solutions, we decided to use the Libcal room booking system from Springshare, which at this time is free for up to three spaces and has tiered subscription rates for additional spaces.

If needed, laptops, cables, and other equipment may be checked out for a few hours from the Technology Services desk. These items are loaded to the patron's library account, and he or she is responsible for any late fees, lost items, or damages.

\section{Current usage}

The Meeting Places opened for reservations in March 2012, and in the first year they were used 224 times. Meeting Place 4, the larger space, was the most popular with 125 reservations, and Meeting Place 2 was reserved 99 times. The Academic Success Series, a weekly undergraduate workshop series cosponsored by the Walker Library and the Advising Center, accounts for nearly 50 of those reservations, but there were also many, many reservations made by students groups and instructors. The User Services secretary, who schedules library instruction sessions, is quick to recommend a Meeting Place to professors who request room use of our classrooms, and if they don't need a computer for each student, most are happy with the arrangement.

We have also found a number of internal uses for the space, ranging from job candidate presentations to staff meetings, and we even held our most recent staff holiday party in Meeting Place 4. While we do have staff areas that we have used in the past for these purposes, the Meeting Places are roomier and more flexible.

\section{The future}

The Meeting Places have been a popular addition to the Walker Library, and we foresee 
additional uses for them in the future as the goals of the Walker Library and MTSU evolve.

For instance, tutoring in the academic departments at MTSU tends to occur during limited daytime hours (mostly 9:00 a.m. to 3:00 p.m.), which does not accommodate the scheduling needs of many of our students. The library's dean has proposed a partnership between the library and academic departments: the library would provide tutoring space due to our flexible furniture configurations, presentation equipment, and operating hours, and the academic departments would provide the tutors. Other college libraries ${ }^{4,5}$ have fostered similar partnerships with great success, and such a program at MTSU allows the Library to be a part of campus recruitment and retention efforts. The Dean has identified Meeting Place 2, the smaller of the two Library meeting spaces, as the site for the tutoring. Meeting Place 2 will host tutoring a few nights a week, but its original purpose will still be maintained.

Because they are so flexible, the possibilities are virtually endless for the Meeting Places.
They have allowed us to accommodate unmet user needs without constructing walls. The Meeting Places were a relatively small investment that have paid off big for our library and for our users.

\section{Notes}

1. http://mtsu.libcal.com/booking/meetingplace2, accessed March 4, 2013.

2. http://mtsu.libcal.com/booking/meetingplace4, accessed March 4, 2013.

3. One of the inspirations for the location and layout of the Meeting Places was the Performance Space at the Georgia Tech Library: http://librarycommons.gatech.edu/lec /performance.php (accessed March 4, 2013).

4. The library at the University of South Florida has a partnership with academic tutors on campus: http://lib.usf.edu/tutoring / (accessed March 4, 2013).

5. Susan Deese-Roberts and Kathleen Keating, "Integrating a Library Strategies Peer Tutoring Program," Research Strategies 17, no. 2: 223-29. n

\section{C\&RL News seeks cover art}

CERL News is looking for images from library collections to feature on upcoming covers.

If you have items in your collections that you think would make attractive $C E R L$ News covers, we would love to see them.

To submit images (or image collections), send URLs for Web-based images or images directly as attachments to David Free at dfree@ala.org. Please include a brief description of the item and your collection.

Images selected to appear as CERL News covers will require a highresolution electronic image (300 dpi or higher) to be submitted prior to the publication date.
Images must be vertically oriented or it must be possible to crop the image to show a detail in vertical format. Items that originate as a standard size ( $8 \times 10,5 \times 7$, etc.) will reproduce better as it will be easier to enlarge or shrink them to fit the cover, as opposed to items of equal width and height (for example, a $5 \times 5$ image). Both color and black-and-white images are accepted.

Works selected must be in the public domain, from institutions that own reproduction rights for the works, or express rights must be obtained from the copyright holder.

Complete guidelines for the submission of cover illustration are available online at crln.acrl.org/site/misc/author.xhtml. 